\title{
Correspondence
}

The Editor,

Journal of Glaciology

SIR,

\section{A reason for resin}

Our experience with electromechanical ice-core drilling in non-fluid-filled bores in polar and in mid-latitude/highaltitude operations has uncovered an ongoing technical difficulty. This problem manifests itself during the lowering of the auger in the bore as the build-up of hoar-frost on the bottom surface of the cutters. Upon impact with the bottom of the bore, this tightly adherent hoar-frost becomes compacted and icy, and prevents the cutting edges of the teeth from contacting the ice. These "snowshoes" can attain a thickness of several millimeters (Fig. 1) and prevent further progress. During our glaciological expedition to the central Tien Shan, Kyrgyzstan, this phenomenon was again encountered at depths of $>50 \mathrm{~m}$ (below the firn-ice transition). We observed that the hoar-frost was tightly adherent to the high carbon steel cutters, but not to adjacent anodized aluminum. We hypothesized that the adhesion was largely a surface-dependent phenomenon and that we could effectively reduce or remove the problem by altering the cutter surface. We discovered that an extremely thin layer of quick-setting epoxy resin prevented adhesion of the hoar-frost and the resulting snow-

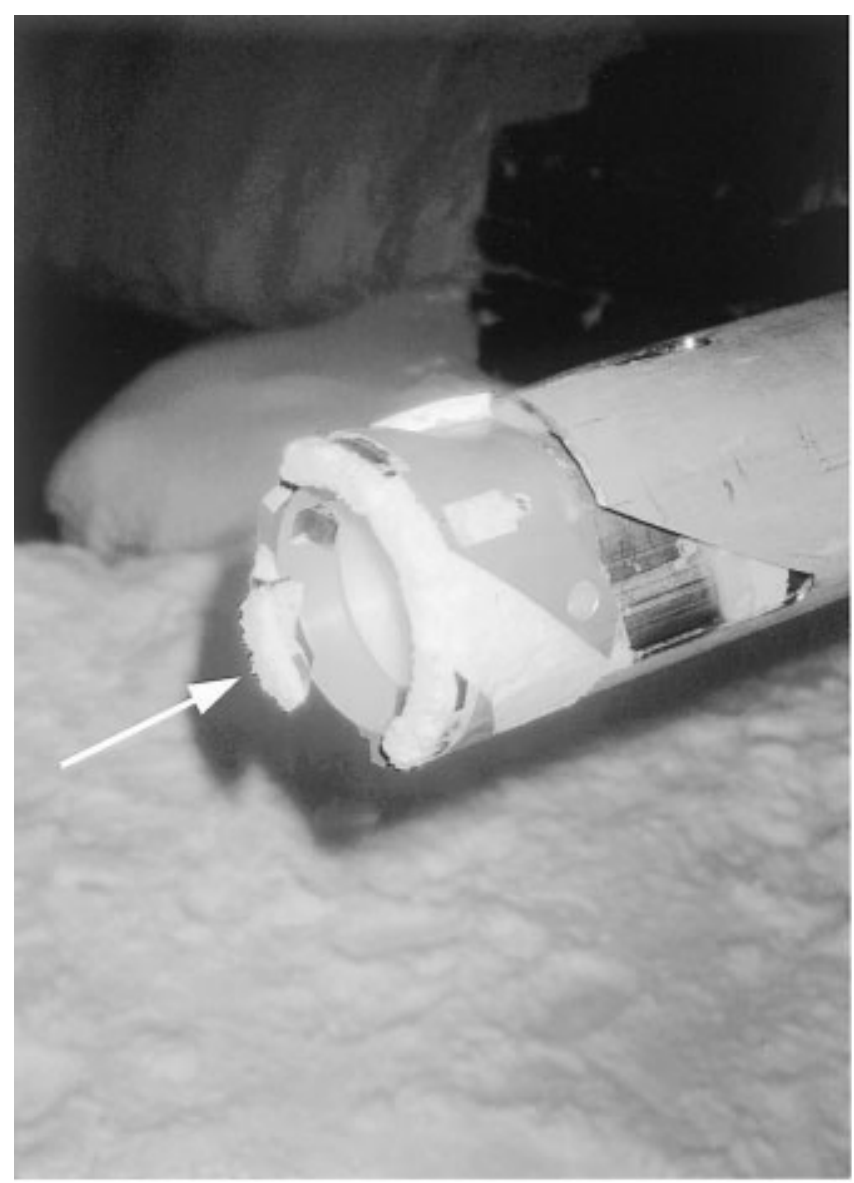

Fig. 1. Photograph of the build-up of hoar-frost on the bottom surface of the cutters on the ECLIPSE drill during night-time drilling on Inylchek glacier, central Tien Shan, Kyrgyzstan. shoes, and resulted in reliable core-cutting and recovery on each trip into the bore. Although we have found this epoxy resin application to be inexpensive, readily available, reasonably durable (approximately $100 \mathrm{~m}$ of core per application) and easy to apply in the field, we suspect that custom application of a TEFLON ${ }^{\mathrm{TM}}$ coating to the affected parts would be the ultimate solution.

We assume that the hoar-frost forms by the following mechanism. In an open bore, stagnant air in contact with the ice walls will eventually attain a relative humidity of $100 \%$. Upon lowering of the drilling head into the bore, the air ahead of the tool must be compressed, and flow past the drilling head through a small annulus. Ahead of the drill, the air is essentially stagnant but experiences sudden acceleration as it moves past the cutter head. This situation is analogous to that at the "leading edge" of aircraft structures; the air experiences expansion as the result of acceleration, and sudden cooling with concomitant lowering of the dew point. The result is the sublimation of hoar-frost on the cutters and cutter head.

Our experience to date has been that hoar-frost/snowshoes are most problematic under conditions of high surface temperatures and high surface humidity (i.e. high absolute humidity at the surface). Pumping of this surface air into the bore on each drilling run appears to exacerbate the problem, a fact that becomes most apparent after the firn-ice transition is crossed. While drilling operations are confined to the firn, air compressed ahead of the lowering drill can move outward into the firn, and frost formation is minimal.

Our drilling equipment has an overall diameter of 108 $\mathrm{mm}(4.25 \mathrm{in})$ and a radial clearance to the bore of approximately $1 \mathrm{~mm}(0.04 \mathrm{in})$. Assuming incompressible flow and a descent velocity of $1 \mathrm{~m} \mathrm{~s}^{-1}$, estimates indicate a fluid velocity of $>16 \mathrm{~m} \mathrm{~s}^{-1}$ in the annulus. As air is in fact compressible, a pressure gradient exists along the length of the drilling apparatus, and the fluid velocity is at a maximum near the cutter head during descent. This, we believe, accounts for the observed hoar-frost accumulation.

\section{ACKNOWLEDGEMENTS}

Funding for this research was provided by the U.S. National Science Foundation paleoclimate program (NSFATM0000561) and U.S. Department of Energy Award No. DE-FE07-00ID13906.

Icefield Instruments Inc.,

Michael D. GerasimofF

Whitehorse, Tukon Territory

r1A 3T5, Canada

Climate Change Research Center,

Cameron P. Wake

University of New Hampshire,

Durham, New Hampshire 03824,

U.S.A.

29 March 2001 